\title{
EDUCAÇÃO FINANCEIRA E A LINGUAGEM: UMA PROPOSTA TRANSVERSAL A PARTIR DO GÊNERO TEXTUAL FÁBULA
}

\author{
Débora da Silva Araújo ${ }^{1}$ \\ Emília Damásia de Sousa Xavier²
}

\section{RESUMO}

O presente artigo tem a meta de contribuir no planejamento das atividades transversais de educação financeira, linguagem e literatura. Sendo as fábulas um gênero textual curto, breve e com uma linguagem simples, que usa sempre animais como exemplo de vida real, apresentamos aqui uma forma de ler e interpretar três fábulas que refletem de forma agradável e prazerosa os valores morais voltados a obediências, honestidade, gratidão, perseverança, lealdade entre outros. De forma transversal, a educação financeira é um tema que conversa com várias outras matérias, sendo essencial para o convívio em sociedade, visando um cidadão pleno, tendo em mente que esse cidadão vai ter que aprender a usar seus recursos financeiros. Assim, esse estudo torna-se um diferencial durante as aulas, pois melhora a consciência moral das crianças perante a sociedade e os leva a compreender o outro e a compreender-se.

Palavras-chave: Transversalidade; Educação Financeira; Linguagem.

\section{ABSTRACT}

This article aims to contribute to the planning of cross-cutting activities of financial education, language and literature. Since fables are a short, brief textual genre with a simple language that always uses animals as an example of real life, we present here a way of reading and interpreting three fables that reflect in a pleasant and pleasurable way the moral values focused on obediences, honesty, gratitude, perseverance, loyalty among others. In a transversal way financial education and a topic that talks with several other subjects it is essential for living in society, aiming at a full citizen, we have to keep in mind that this citizen will have to learn to use his financial resources. Thus, this study becomes a charm during classes, because it improves the moral conscience of children before society and leads them to understand and understand each other.

Keywords: Transversality. Financial Education. Language

\footnotetext{
${ }^{1}$ Cursando Doutorado em Ciências da Educação pela Universidad de Desarrollo Sustentable UDS - PY; Mestre em Educação pela Universidad Interamericana - PY (2020), graduada em Licenciatura plena em Letras / Português e Espanhol pela Universidade Estadual de Mato Grasso UNEMAT (2011). Atualmente, é Professora regente de língua portuguesa na escola estadual Waldemon Moraes Coelho e na Escola estadual Ulisses Guimarães no município de Campo Verde 2020. E-mail: deboraprof.moraes@hotmail.com

${ }^{2}$ Cursando Doutorado em Ciências da Educação pela Universidad de Desarrollo Sustentable UDS - PY (2020), Mestre em Ciências da Educação pela Universidad de Desarrollo Sustentable UDS - PY (2020), graduação em licenciatura plena em matemática UFMT (2002), graduação em Administração pela UFMT (2013). Graduação em Ciências Contábeis pela Universidade Estadual do Tocantins (2009). Pós-graduação em gestão pública UFMT (2012). Pósgraduação em formação de orientadores acadêmicos para EaD UFMT (2008). Pós-graduação em Docência Multidisciplinar na Ed. Inf. e anos iniciais do Ensino Fundamental, Faculdade de Ciências Jurídicas e Sociais Aplicadas do Araguaia, FACISA, Brasil (2004). Atualmente é professora efetiva na disciplina de matemática na Prefeitura Municipal de Ribeirão Cascalheira. E-mail: emiliadamasia@gmail.com
} 


\section{RESUMEN}

Este artículo tiene como objetivo contribuir a la planificación de actividades transversales de educación financiera, lengua y literatura. Dado que las fábulas son un género textual corto y breve con un lenguaje sencillo que siempre utiliza a los animales como ejemplo de la vida real, aquí presentamos una forma de leer e interpretar tres fábulas que reflejan de una manera agradable y placentera los valores morales centrados en obediencias, honestidad, gratitud, perseverancia, lealtad entre otros. De manera transversal la educación financiera y un tema que habla con varios otros temas es fundamental para vivir en la sociedad, apuntando a un ciudadano pleno, debemos tener en cuenta que este ciudadano tendrá que aprender a utilizar sus recursos económicos. Por lo tanto, este estudio se convierte en un encanto durante las clases, porque mejora la conciencia moral de los niños ante la sociedad y los lleva a entenderse y entenderse.

Palabras clave: Transversalidad; Educación Financiera; Idioma.

\section{INTRODUÇÃO}

O presente artigo traz como destaque o tema transversal educação financeira que permeia as disciplinas da Educação Básica. Ao abordar esse tema, o professor leva os alunos a refletirem para que eles tenham condições de construir conceitos em vez de apenas coletar informações, considerando que os temas transversais são mais uma forma de inserir as questões sociais nos currículos escolares. Segundo o Ministério da Educação (MEC), são temas que estão voltados para compreensão e para a construção da realidade social e dos direitos relacionados à vida pessoal e coletiva, servindo, também, para estimular a reflexão e contribuindo para uma visão crítica em relação à prática e aos valores inseridos nas disciplinas e no meio social.

Este artigo tem como objetivo principal despertar o interesse do aluno pela leitura e pela interpretação de textos que, consequentemente, os induzem a compreender e o significado valorativo de que a educação financeira através das fábulas e suas características moralizantes. Com esse tema em evidência, o professor deve instigar o aluno para a necessidade de possuir determinado produto e, assim, criar a noção de consumo consciente, sendo esse um momento oportuno para prepará-los para a organização de sua vida financeira. Tudo isso pautado nos PCNs, criados pelo governo federal para propiciar subsídios para a elaboração e reelaboração do currículo, tendo em vista um projeto pedagógico em função da cidadania do aluno numa escola em que se aprende de maneira mais eficiente. 
O artigo encontra-se dividido em quatro tópicos, o primeiro momento foi a transversalidade na Educação Básica, enquanto o segundo tópico apresenta a educação financeira e linguagem, e o terceiro assunto trata do gênero fábula e suas características moralizantes. Enquanto o tópico quarto, subdivide-se em proposta transversal valores e determinação no mundo encantado das fábulas; e, também, nos nomes das fábulas: educação financeira e a fábula dos três ratinhos cegos; educação financeira com a fábula da Cigarra e a Formiga; e educação financeira com a fábula da Lebre e a Tartaruga. Em suma, serão tecidas algumas considerações conclusivas sobre o tema em questão.

\section{TRANSVERSALIDADE NA EDUCAÇÃO BÁSICA}

Conforme apresentam os Parâmetros Nacionais Curriculares (PCN) (BRASIL, 1998), a transversalidade pressupõe um trabalho conectado das áreas e um compromisso das relações interpessoais e sociais escolares com as questões que estão envolvidas nos temas propostos pela educação básica conforme a necessidade do momento. Os PCNs (BRASIL, 1998) propõem que esse trabalho interligado aborde uma educação a serviço da cidadania, preocupada com a formação de cidadãos com direitos e deveres aptos para participarem ativamente da vida em sociedade.

Conforme trazem os PCNs (BRASIL, 1998), os temas transversais fomentam o desenvolvimento da democracia, nos quais otimiza a participação dos indivíduos na construção social, pois a transversalidade é entendida como forma de organizar o trabalho didático, em que alguns temas são integrados nas áreas convencionais, estando presente em todas elas, uma vez que nas práticas pedagógicas, a interdisciplinaridade e a transversalidade alimentam-se mutualmente.

Diante disso, encontra-se, nos PCN (BRASIL, 1998), que, em presença dos temas transversais, nenhuma área sozinha isoladamente é suficiente para abarcar esse tema na sua totalidade, pois, quando se utilizam diferentes maneiras de observar um objeto, a possibilidade de construção de conhecimento é mais ampla. Diante do exposto, usa-se a transversalidade para o tema escolhido e deve ser trabalhado perpassando por todas as disciplinas, fazendo 
um diálogo entre si para que haja uma contextualização e faça significado para os estudantes.

Neste sentido, a Base Nacional Comum Curricular (BNCC) apresenta que:

A Contextualização é uma tarefa imprescindível para o conhecimento histórico. Com base em níveis variados de exigência, das operações mais simples às mais elaboradas, os alunos devem ser instigados a aprender a contextualizar. [...] Portanto, os estudantes devem identificar, em um contexto, o momento em que uma circunstância histórica é analisada e as condições específicas daquele momento, inserindo o evento em um quadro mais amplo de referências sociais, culturais e econômicas (BNCC, 2017, p. 399).

Este artigo traz o gênero fábula como proposta de leitura e contextualiza com o aprendizado da educação financeira através das interpretações de fábulas, porque essa contextualização está pautada em uma educação de valores e atitudes, pois não trabalha o conteúdo pelo conteúdo, já que ele está a serviço do desenvolvimento das competências, das habilidades, de atitudes, de valores, isso faz com que os alunos participem mais ativamente da sociedade. Sendo assim, a BNCC expõe que

\begin{abstract}
A aprendizagem deve valorizar a aplicação dos conhecimentos na vida individual, nos projetos de vida, no mundo do trabalho, favorecendo o protagonismo dos estudantes no enfrentamento de questões sobre consumo, energia, segurança, ambiente, saúde, entre outras (BNCC, 2017, p. 549),
\end{abstract}

Diante do exposto, para que se alcance os objetivos almejados, é necessário que as escolas façam mudanças pedagógicas para que os temas transversais sejam abordados com toda a sua riqueza, possibilidades e potencialidades, visto que, na educação contemporânea, o professor não é detentor do saber, sendo apenas mediador dos alunos ativos nos processos que participam e os conteúdos vão sendo construídos juntamente com toda equipe escolar.

O projeto de transversalidade deve que ser contínuo, pois os temas abordados são questões que não se esgotam dentro de um ano, por esse motivo deve ser um trabalho que tenha continuidade para alcançar todos os sujeitos do processo educacional. Segundo os PCN (1998), a formulação e implementação do projeto educativo já iniciam um processo de formação e mudança (BRASIL, 
1998, p. 38). Por isso, as instruções interdisciplinares lutam contra as práticas de ensino descontextualizado da realidade, pois implica a abrangência do conteúdo.

Essa forma inovadora de pensar a educação traz privilégios nas práticas pedagógicas cooperativas, na qual estimula a reflexão, a criatividade e, principalmente, o pensamento crítico. De acordo com os PCN (BRASIL, 1998), cabe aos professores propiciarem aos alunos uma abordagem mais significativa e contextualizada. Segundo Libâneo (1994, p. 22), o professor exerce uma importante função na construção da sociedade, pois a qualidade da educação está diretamente relacionada aos professores.

Pensando na abrangência de conteúdo dentro de um contexto esquematizado, viu-se a necessidade de unir as linguagens das fábulas contextualizadas ao entendimento das mesmas com uma grande reflexão para ser usada no ensino da educação financeira para buscar despertar o interesse dos alunos com conteúdo dentro de um contexto que possam colaborar para o entendimento do mundo real. Para isso, usou-se a literatura para introduzir, segundo a BNCC, pois pode-se contextualizar o imaginário ao real.

O contato com histórias, contos, fábulas, poemas, cordéis propicia a familiaridade com livros, com diferentes gêneros literários, a diferenciação entre ilustrações e escrita, a aprendizagem da direção da escrita e as formas corretas de manipulação de livros. Nesse convívio com textos escritos, as crianças vão construindo hipóteses sobre a escrita" (BNCC, 2020, p. 42).

Perante 0 que foi apresentado sobre transversalidade e interdisciplinaridade, faz necessário fomentar o quanto a consciência da importância desse conteúdo é essencial para garantir-lhes tratamento apropriado, em que se vise um desenvolvimento amplo, harmônico e equilibrado dos alunos, tendo em vista sua vinculação à função social da escola (BRASIL, 1998 , p. 53) e, ao mesmo tempo, propor-se o aprimoramento dos currículos atuais. 


\section{EDUCAÇÃO FINANCEIRA E LINGUAGEM}

Diante do cenário atual, a vida financeira das pessoas tem ganhado muito espaço no cenário econômico. No âmbito escolar, o que tem ganhado espaço é a reflexão da educação financeira. A Organização para Cooperação e Desenvolvimento Econômico (OCDE) preocupa-se com o consumidor investidor, ou seja, o mercado financeiro, mas direciona uma grande preocupação para as escolas segundo a OCDE (2005) "A educação financeira deve começar na escola. As pessoas devem ser educadas sobre questões financeiras o mais cedo possível em suas vidas" (OCDE, 2005 p. 6). Para a organização, o quanto antes eles forem preparados para esse mundo melhor.

Como afirma Sousa (2018), a grandeza de alguém vem da possibilidade de partilha e da atitude de não se elevar pela diminuição das outras pessoas. Essa é a nova reflexão que a educação financeira e a linguagem nos trazem enquanto educadores. Assim, devemos ser e ter mais empatia para com aqueles que precisam atenção e cuidados, já que aprendemos muito mais quando contribuímos com o aprendizado do outro.

No Brasil, a desigualdade e a má distribuição de renda são problemas econômicos que afetam as famílias. A escola poderia preparar os alunos dentro da realidade econômica do país. Segundo Cerbasi (2019), "seria muito importante adquirir noções sobre o funcionamento de bancos, economia doméstica, orçamento e juros compostos. Todos os que concluírem a escola vão lidar, um dia com esses elementos" (CERBASI, 2019 p. 34). O autor defende que a escola deveria reformular o currículo, preparando o trabalhador para a vida, pelo menos, é o que deveria ser.

Para Costa (2019), deve se mostrar os valores essenciais, que estão além do dinheiro. As pessoas devem nos valorizar pelo o que somos e podemos oferecer e não pelo o que ganham ou tem de bens materiais. Importante colocar o quanto os estudos podem contribuir se o aluno for dedicado e esforçado. Qualquer aluno com essas virtudes terá sucesso em qualquer carreira que escolher.

É preciso alfabetizar as crianças no tema educação financeira, pois o dinheiro tem uma linguagem que pode ser identificada nas fábulas, por exemplo, nas aulas de língua portuguesa ou de literatura infantil. Os alunos poderão tomar 
consciência dos sonhos, desejos e dos valores éticos e morais para construir uma aprendizagem que contribuirá para serem adultos prósperos e organizados financeiramente.

Segundo Perissé (2014), "a leitura (do mundo e das palavras) descortina possibilidades para além do cotidiano ou de circunstâncias eventualmente limitantes. A leitura nos faz almejar e pertencer a outros espaços e tempos" (PERISSÉ, 2014 p. 86). Para o autor, esse aprendizado poderá adotar nos alunos práticas de aprendizagem humanizadas por incentivar a socialização entre os alunos. Nesse momento, o papel da escola é preparar ativamente os alunos para a vida.

Diante deste estudo, foi escolhido o gênero textual fábula, que tem por objetivo identificar a produção de significados valorativos relacionados à educação financeira. Ressaltamos que o presente artigo é uma proposta para os professores do Ensino Fundamental desenvolverem a temática em sala de aula, sendo o objetivo principal despertar o interesse do aluno pela leitura e interpretação de textos que, consequentemente, os levaram a compreender o significado valorativo que a educação financeira oferece através das fábulas.

\section{O GÊNERO FÁBULA E SUAS CARACTERÍSTICAS MORALIZANTES}

As teorias envolvendo os gêneros textuais parece ser algo novo, mas está bem longe disso. Seus estudos começaram com Platão, que iniciou a análise dos gêneros literários e foi aprofundada por Aristóteles. Atualmente, os estudos não mais se prendem à seara da literatura. Dessa forma, reconhecem-se vários tipos de gêneros que se encaixam nas mais diversas áreas de conhecimento, possibilitando novos estudos e teorias sobre o tema.

Sendo assim, Marcuschi (2008, p. 155) manifesta:

Os gêneros textuais são os textos que encontramos em nossa vida diária e que apresentam padrões sociocomunicativos característicos definidos por composições funcionais, objetivos enunciativos e estilos concretamente realizados na integração de forças históricas, institucionais e técnicas (MARCUSCHI, 2008, p. 155).

Em sala de aula, o ensino sob a perspectiva dos gêneros modernizou-se. Antes se tinha um ensino de base tradicional, desvinculado "(d)o uso autêntico 
da língua" como afirmam Brum e Daniel (2006, p. 12), e a literatura passou por um momento de transição. $O$ ensino em si tem sido direcionado para um trabalho com o uso de diversos gêneros textuais. Acerca disso, Schneuwly e Dolz (2004, p. 75), afirmam que a escola, "na sua missão de ensinar os alunos a escrever, a ler e a falar, forçosamente, sempre trabalhou, com os gêneros" e ainda que "O trabalho escolar, no domínio da produção da linguagem, faz-se sobre os gêneros, quer se queira ou não" (SCHNEUWLY; DOLZ 2004, p. 51).

Partindo dessas teorias, percebe-se que os gêneros fazem parte do cotidiano de todos, sendo mais perceptível nos espaços escolares. A fábulas, o objeto do presente artigo, são textos moralizantes que, de certa forma, partem de enredos ficcionais para transmitir conhecimento. La Fontaine é considerado uma das mais expressivas representatividades do que tange ao mundo das fábulas.

A sua grande obra, Fábulas, dividida em três momentos, pautou-se na estilística textual de Esopo, escritor grego, versando sobre vaidade, estupidez e agressividade humanas por meio de animais. O fabulista La Fontaine passou com o tempo a ser considerado o pai da fábula moderna.

Seus escritos são considerados pelo próprio autor como uma pintura em que os indivíduos podem encontrar o próprio retrato. Algumas fábulas escritas e reescritas por ele são A Lebre e a Tartaruga, O Homem, A Cegonha e a Raposa, O Menino e a Mula, O Leão e o Rato, e O Carvalho e o Caniço, a Raposa e a Uva. Posto isso, o gênero fábula, assim como outros gêneros narrativos, traz experiências e o modo de vida dos povos, já que é por meio das histórias que os alunos aprendem boa parte do que precisam saber para viver em sociedade.

Sobre o uso de histórias para educar, Abramovich (1991, p. 162) nos aponta que:

[...] ouvir ou ler histórias é uma possibilidade que a criança encontra para descobrir o mundo imenso dos conflitos, dos impasses e as soluções que todos os seres humanos vivem e atravessam ao longo da vida. Assim, é através de uma atividade prazerosa de leitura ou ouvir histórias que se pode descobrir outro lugar, outros tempos, outros modos de agir, de pensar e ser (ABRAMOVICH, 1991, p. 162).

Portanto, como afirma Marcuschi (2008), os textos podem ser considerados uma entidade de comunicação e um artefato histórico. Podem ser 
entendidos como uma manifestação do pensamento de um dado autor, que será decodificado por um leitor de acordo com seu conhecimento linguístico e extralinguístico. Já os gêneros, segundo Schneuwly e Dolz (2004), são instrumentos culturais disponíveis nas interações sociais, historicamente mutáveis e, consequentemente, relativamente estáveis. Emergem em diferentes domínios discursivos e se concretizam em textos, que são singulares e são extremamente necessários na rotina escolar.

\section{METODOLOGIA: PROPOSTA TRANSVERSAL "VALORES E DETERMINAÇÃO NO MUNDO ENCANTADO DAS FÁBULAS"}

Em 2019, a educação financeira passou a fazer parte do currículo da Base Nacional Comum Curricular (BNCC), sendo esta abordada de forma transversal as disciplinas curriculares, o que significa que passou a ser matéria obrigatória nas escolas públicas e privadas a partir de 2020.

Para Perissé (2014), "quando, porém, adotamos os temas transversais como eixos unificados da ação educativa, em torno dos quais todas as disciplinas têm algo a dizer, a formação integral e destacada como o objeto de todos os envolvidos" (PERISSÉ, 2014 p. 7). Segundo o autor, esta é a melhor experiência que o professor e aluno podem ter, pois os temas transversais permitem uma integração entre as pessoas e as disciplinas, estimulando a curiosidade e a sabedoria entre estudantes e professores.

\section{EDUCAÇÃO FINANCEIRA E A FÁBULA DOS TRÊS RATINHOS CEGOS}

Segundo Perissé (2014) "a palavra, o silêncio e a imagem são um tripé na qual se apoia a realidade do encontro interpessoal" (PERISSÉ, 2014 p. 82). Para o autor, a capacidade de comunicação através da escrita nos leva a refletir e aprender a sua riqueza.

O conto infantil, Os três ratinhos cegos, diz que existia um reino de ratos que sobrava alimentos, mas, de repente, começou a falta de comida. Então, o rei decidiu que, a partir daquele dia, todos deveriam trabalhar para poder comer, exceto aqueles que tivessem alguma deficiência física. Assim, os três ratinhos, orientados pelo o irmão mais velho, foram até o rei se fingindo de cegos para 
fugir do trabalho e poder comer de graça. Ao saírem do reino, encontram com o grande gato e tiveram que lutar e perderam os óculos. Ao voltar às presas para o reino, depararam-se com o rei que logo viu que eles não eram cegos. O rei, então, determinou que os três, para continuar vivendo no reino, teriam de trabalhar dobrado.

A lição dessa história é que não existe direto se não tiver dever e que as ações erradas começaram quando os irmãos mais novos concordaram em mentir para o rei. Ou seja, quando queremos algo na vida devemos começar de baixo, ter conhecimento de base e ir subindo aos poucos, devagar com experiência e conhecimento. Fazendo as coisas certas, com certeza, teremos sucesso na vida, já que vida boa todos merecem, mas, para que isso aconteça, é preciso muito trabalho e honestidade.

\section{EDUCAÇÃO FINANCEIRA COM A FÁBULA DA CIGARRA E A FORMIGA}

A versão de Esopo (620 a.C. - 564 a.C.) foi um escritor da Grécia Antiga que ficou eternizado pela sua coletânea de fábulas que passaram a integrar a tradição popular oral, sendo a fábula $A$ Cigarra e a Formiga um clássico de Esopo.

Essa famosa fábula retrata o quanto a cigarra só se preocupava em viver a vida, cantando, como se o amanhã não fosse existir, importando, para ela, somente 0 presente, enquanto a formiga trabalhava todos os dias disciplinadamente. Ao chegar o inverno, a formiga tinha um grande estoque de alimento, enquanto a cigarra padecia com fome e sem abrigo. Quando o inverno chega, a cigarra procura as formigas em busca de abrigo e comida.

A lição de moral dessa história é simples e direta sobre a importância e o valor do trabalho. A cigarra e a formiga apresentam posturas opostas durante a vida, sendo a formiga bem esforçada e trabalhadeira e a cigarra bem preguiçosa e festiva.

Segundo Costa (2019), um dos pilares da educação é a generosidade, devemos ensinar nossos alunos essa boa ação. As formigas poderiam ter sido mais generosas com a amiga que cantava com muita alegria para alegrar os dias difíceis de trabalho árduo das formigas. 
Segundo Perissé (2014) "outra coisa é projetar com a imaginação e a inteligência uma vivência melhor no futuro" (PERISSÉ, 2014 p. 84). Para o autor projetar com a imaginação o aprendizado dos alunos possibilita-os um conhecimento do mundo da educação financeira que pode ser ensinada nas escolas. Esse mundo linguístico fabuloso nos remete a vários valores e disciplina que deve ser apresentado as crianças.

$\mathrm{Na}$ educação financeira, devemos ser como a formiga independente e responsáveis por nós mesmos. Até nos momentos em que temos vontade de descansar e aproveitar a vida como a cigarra, é necessário pensar no futuro e batalhar por ele.

\section{EDUCAÇÃO FINANCEIRA COM A FÁBULA DA LEBRE E A TARTARUGA}

Outra fábula de Esopo que muito nos ensina no universo da educação financeira é $A$ Lebre e a Tartaruga. Assim, podemos dizer que as fábulas são contos de moralidade popular, uma lição de inteligência e justiça que remetem sempre aos comportamentos valorativos

Essa fábula traz um ensinamento importantíssimo sobre a regularidade dos investimentos. Nessa história, ou você tem visão de tartaruga ou você não conseguirá cruzar a linha de chegada e vencer essa corrida.

Como diz Perissé (2014) "os sonhos não vêm do nada. Para sonhar, precisamos ter conhecimento adequado ou ao menos o vislumbre de novas realidade" (PERISSÉ, 2014 p. 86). Para o autor, os sonhos serão realizados quando temos disciplina e planejamento para alcançá-lo.

A lebre, ao longo da fábula, sai correndo na frente disparada e depois, convencida da sua rapidez e por estar bem a frente, resolveu parar e descansar, enquanto a tartaruga seguia no seu ritmo devagar e sempre com muita determinação. Com isso, a tartaruga passou a lebre e cruzou a linha de chegada.

Os ensinamentos dessa fábula para o mundo da educação financeira dizem que o progresso só acontece se acreditarmos e acima de tudo devemos ser pessoas perseverantes. Para poupar, precisamos diminuir gastos desnecessários e sermos sempre disciplinados como a tartaruga. 
$\mathrm{Na}$ vida, a lebre pode até ter mais glamour, mais é a tartaruga que ganha a corrida devido a sua determinação, disciplina e regularidade nos treinos e assim deve ser nossa vida financeira.

\section{CONSIDERAÇÕES FINAIS}

Educação Financeira ainda é uma matéria pouco trabalhada nas escolas, incluída na Base em 2019, poucos brasileiros têm acesso a ela. Ao estabelecer o que a BNCC apregoa, o MEC e as instituições financeiras asseveram que 0 ensino de Educação Financeira nas escolas ajudará muito na conceituação e, também, na metodologia usada nesse tipo de aprendizagem para surtir o efeito desejado na aprendizagem.

Dentro do contexto linguístico estabelecido nesse artigo, a educação financeira apresenta-se como eixos temáticos transversais de ensino, assim sendo relaciona-se com as fábulas e seus resultados, estando voltadas aos valores éticos e morais. As fábulas são obras literárias que oferecem nas suas entrelinhas conceitos sobre deveres e direitos na vida social, levando os alunos a terem visão de mundo que promova compreensão do certo e do errado. $O$ mundo imaginário é uma base de diálogo construtivo e humanizador que apresenta afeto e valores para toda a vida.

Frente a estas reflexões apresentadas no presente artigo, destacamos a importância de incluir no currículo de linguagem forma transversal a educação financeira nas escolas desde os primeiros anos de escolarização. Podemos concluir, assim, conforme afirmam D`Aquino e Maldonado (2012) que "a criança pequena funciona na lei do desejo e precisa dos limites para aprender a tolerar as frustrações, fazer escolhas e renúncias, ter capacidades de superar obstáculos e paciência para desenvolver suas habilidades, ser capaz de cuidar bem de si mesma” (D`AQUINO; MALDONADO, 2012, p. 54).

Diante da necessidade de abordar a educação financeira nas escolas com as crianças ainda pequenas, considerando suas particularidades, ressaltamos que a linguagem apresentada, através das fábulas, poderá direcionar o aprendizado de forma agradável e prazeroso da capacidade de pensar logicamente dos pequenos leitores. 


\section{REFERÊNCIAS BIBLIOGRÁFICAS}

ABRAMOVICH, Fany. Literatura infantil: gostosuras e bobices. 2ed. São Paulo. Scipione, 1991.

BNCC. Base Nacional Comum Curricular. Disponível em: http://basenacionalcmum.mec.gov.br/images/BNCC El EF 110518 versaofinalsite.pdf. acesso em 15 de setembro 2020.

BRASIL. Secretaria de Educação Fundamental. Parâmetros Curriculares Nacionais: apresentação dos temas transversais, ética / Secretaria de Educação Fundamental. - Brasília: MEC/SEF, 1997.

BRASIL. Secretaria de Educação Fundamental. Parâmetros curriculares nacionais: introdução aos parâmetros curriculares nacionais / Secretaria de Educação Fundamental. - Brasília: MEC/SEF, 1997.

BRUN, E.P; DANIEL, M.E.B. Da gramática da frase à teoria dos gêneros. Papéis, Campo Grande, MS, v. 10, n. 19, p. 11-30, jan/jun. 2006.

CERBASI, G. Pais inteligentes enriquecem seus filhos. Rio de Janeiro: sextate,2019.

COSTA, C.E.F. Sim! Dinheiro e assunto para criança, São Paulo: Literare Books International, 2019.

D'AQUINO, C. MALDONADO, M.T. Educar para consumo: Como lidar com desejos de crianças e adolescentes - Campinas. SP: Papirus 7 mares, 2012.

LIBÂNEO, J. C. Didática. São Paulo: Cortez, 1994.

MARCUSCHI, L.A. Produção textual: análise de gêneros e compreensão. São Paulo: Parábola Editorial, 2008. 
MARCUSCHI, L.A. Gêneros textuais emergentes no contexto da tecnologia digital. In: MARCUSCHI, L. A.; XAVIER, A. C. (Orgs.) Hipertexto e gêneros digitais: novas formas de construção de sentido. Rio de Janeiro: Lucerna, 2005.

OCDE (Organização e Desenvolvimento Econômico) OECD'S Financial Education Project. Disponível em: http://www.oecd.org. acesso em 05 setembro de 2020.

PERISSÉ, G. Formação integral: educação financeira como tema transversal: São Paulo: Editora DSOP, 2014.

SCHNEUWLY, B.; DOLZ, J. Gêneros orais e escritos na escola. Campinas, São Paulo: Mercado das Letras, 2004.

SOUSA, M de. CORTELLA, M.S. Vamos pensar + um pouco? Lições ilustradas com a turma da Mônica. São Paulo: Cortez, 2018. 